\title{
Pediatric Inflammatory Bowel Disease: A Review of Immune Homeostasis and Genetics with an Emphasis on the IL-10 Pathway
}

\author{
Tony R Lin 1 , Joanna Floros ${ }^{2,3}$ and Zhenwu Lin ${ }^{4 *}$ \\ ${ }^{1}$ College of Medicine, Pennsylvania State University, USA \\ ${ }^{2}$ Department of Pediatrics and, Pennsylvania State University, USA \\ ${ }^{3}$ Department of Obstetrics and Pennsylvania State University, USA \\ ${ }^{4}$ Department of Radiology, University of Pennsylvania, USA
}

Received: January 17, 2018; Published: January 31, 2018

*Corresponding author: Zhenwu Lin, Senior Research Scientist, Department of Radiology, Perelman School of Medicine, University of Pennsylvania, Philadelphia, USA, Tel: 1-717-315-6797; Fax: 1-717-531-0215; Email: zxl13@psu.edu

\begin{abstract}
Inflammatory bowel disease (IBD) is an auto-immune condition characterized by chronic gastrointestinal inflammation. The incidence of pediatric IBD, particularly the early onset disease subtypes, has been increasing internationally. In contrast to later-onset IBD, recent literature indicates that early-onset (between 3 - 5 years) and very early-onset (between 0 - 2 years) patients present with a more severe and aggressive disease. A comprehensive review of the literature indicates that the gut microbiome, which is heavily influenced in the early life, is reduced in IBD patients and hence plays a role in regulating gastrointestinal homeostasis. While many genes have been confirmed to be associated with IBD, only a portion of those genes have been shown to cause pediatric IBD.

The IL-10/STAT3 pathway is a well-studied gene pathway as is, involved in maintaining immune homeostasis in both acute and chronic inflammation. Accumulating evidence indicates that IL-10/STAT3 pathway is a key player in pediatric IBD. New mutations identified within the IL-10 pathway have been shown to disrupt immune homeostasis and cause gastrointestinal inflammation. Furthermore, significant epistatic interactions have been demonstrated between different single-nucleotide polymorphisms of IL-10 genes suggesting that understanding gene interactions within the IL-10//STAT3 pathway may be key to understanding more about IBD pathogenesis. Heme oxygenase 1 (HO-1) is speculated to be regulated by the IL-10/STAT3 pathway and hence involved in pediatric IBD formation. This review aims to provide an overview of pediatric IBD and discuss the role of the gut microbiome, IL-10/STAT3 pathway, and HO-1 gene in modulating immune homeostasis in IBD pathogenesis.
\end{abstract}

Keywords: Inflammatory bowel disease; Crohn's disease; Ulcerative colitis; Pediatric; Early onset; Very early-onset; IL-10, STAT3; HO-1

Abbreviations: IBD: Inflammatory Bowel Disease; UC: Ulcerative Colitis; CD: Crohn's Disease; NVDW: Neutrophil Volume Distribution width; PCDAI: Pediatric Crohn's Disease Activity Index;

\section{Introduction}

Inflammatory bowel disease (IBD), mostly ulcerative colitis (UC) and Crohn's disease (CD), is a chronic auto-immune condition affecting $0.4 \%$ to $0.6 \%$ of the North American population [1]. IBD is characterized by inflammatory destruction of the gastrointestinal mucosa [2]. IBD manifests as both gastrointestinal and extra-intestinal symptoms such as diarrhea, abdominal pain, hematochezia, and joint pain $[3,4]$. The exact etiology of IBD is unknown; however, it has been postulated that IBD is a multifactorial disease caused by an immunological response to host gut microbiome and is modulated by a combination of genetics and environmental exposures [5,6]. Hence, disease severity and presentation often depends upon a variety of factors including diet, race, environment, sex, age, and life style [7]. According to the Montreal classification, IBD is classified based on age of disease onset as A1 (<17 years), A2 (17 - 40 years), or A3 ( $>40$ years). A1 IBD can be further sub-classified as either A1a ( 0 - 9 years) or A1b (10 - 16 years). Some papers make a special distinction between early-onset (EO; disease onset between 3 - 5 years) or very early- 
onset (VEO; disease onset between 0 - 2 years) IBD [8-12] due to the unique phenotypes found in that age range discussed later in this review.

\section{Epidemiology of Pediatric IBD}

In recent years, the incidence and prevalence of IBD has been steadily increasing worldwide [13] and especially in the pediatric population (< 17 years) [14]. Approximately $25 \%$ of IBD patients contract the disease within their pediatric years [15] and it is estimated that the incidence of IBD has increased by over $50 \%$ over the past decade in children younger than 5 years $[14,16]$. A recent cohort study done in Ontario, Canada, found that IBD rates, while unchanging in the elderly, have been increasing significantly amongst the pediatric and adult populations from 1999 to 2008. The authors report that the incidence of IBD in patients younger than 10 years old and between $10-19$ years old increased by 9.7\% and 3.8\% per year, respectively [17]. Other North American studies show an EO-IBD incidence rate to be anywhere from $6 \%$ to $10 \%[8,18]$. In France, a population based study of 1,412 pediatric patients showed a $116 \%$ increase in the incidence of EO-IBD [19]. VEO-IBD is a rare phenotype; in some studies, it occurs in only 21 of 2022 pediatric patients [20-22]. While pediatric IBD has mostly been studied within the United States of America, Canada, and European countries [23-25], it is clear that cases of pediatric IBD are increasing in other nations, such as China [26], Saudi Arabia [27], and Turkey [28], with similar clinical presentations. These studies cement the idea that pediatric IBD is a growing international problem, which needs to be understood.

\section{Clinical Presentation and Diagnosis of Pediatric IBD}

Recent literature supports the hypothesis that EO-IBD and VEO-IBD presents with a more aggressive and severe phenotype compared to later and adult-onset IBD [12,29-33]. In an agegroup comparison of 160 IBD patients, those diagnosed between 5-10 years of age had greater IBD activity and extent than those diagnosed between 11-16 years of age [29]. The most common initial clinical findings are isolated colitis and rectal bleeding [29]. Furthermore, EO-IBD patients are more likely to be on immunomodulation therapy and require surgery compared to older patients [12,18,34-37]. In one study, Aloi et al analyzed a group of 506 pediatric IBD patients in Italy. The authors reported a higher prevalence of UC in the early-onset and a higher prevalence of $\mathrm{CD}$ in the later-onset populations. EO-UC was more likely to initially present with pancolitis. In addition, EO-CD was more likely to present with isolated colonic and upper gastrointestinal disease instead of ileocolic disease as commonly seen in older children [12].

A recent systematic review on pediatric IBD from 41 studies of 3505 CD patients, 2071 UC patients, and 461 indeterminate colitis patients indicated growth failure in CD patients more often than in UC patients, and the surgery rate in CD was much higher than in UC [38]. It is important for clinicians to be able to accurately recognize and diagnose IBD in a timely fashion so that treatment can be initiated as soon as possible. Although most patients have delayed growth charts, published studies indicate that pediatric patients catch up and reach appropriate adult height levels [39]. Delay in treatment can result in stunted growth development secondary to chronic inflammation and malnutrition among other factors [40]. However, diagnosis of EO-IBD can be difficult. Firstly, symptoms of EO-IBD are broad and non-specific. This results in a wide range of both gastrointestinal and extra-intestinal manifestations that can complicate diagnosis [3]. The non-specificity of findings can help explain why indeterminate IBD (instances of colitis in which classification as either CD or UC is unclear) and UC make up the majority of EO-IBD cases despite the fact that $\mathrm{CD}$ is the most common overall form of IBD $[12,19]$.

Secondly, the gold standard for assessing IBD is an endoscopy study with biopsies. However, these tests are invasive and not often utilized, especially in pediatric patients $[3,41]$. Compounding this problem is that histological studies are often inconclusive or show non-specific findings [3]. These factors all lead to delayed diagnosis and contribute to extensive disease upon initial presentation $[37,42]$. Recently, several studies have investigated markers that can aid in diagnosis. Aydemir et al reported significantly higher neutrophil volume distribution width (NVDW) in UC and CD patients compared to normal controls and propose NVDW as an objective parameter for IBD diagnosis [41]. Eosinophilia-associated basal plasmacytosis has been postulated as a sensitive and early histological feature of inflammatory bowel disease [43]. Recently, certain single stranded RNA sequences, 18-24 nucleotides long, known as MicroRNA (MiRNA) [44], have been proposed to be associated with IBD [45] and could potentially be utilized as a diagnostic marker. Further research is still needed in this regard.

\section{Gut Microbiome in Pediatric IBD}

In addition to genetics, emerging research indicates a role of the gut microbiome in IBD pathophysiology [46]. Following birth, the neonatal immune system interacts with the gut microbiome and becomes resistant or susceptible to inflammation [47]. It has been recognized that $\mathrm{Th} 1$, Th2, Th17, and regulatory T cells play an important role in IBD development $[48,49]$. Paneth cells comprise an important part of the gut immunity and Paneth cell dysfunction has been associated with gut microbial dysbiosis and IBD [50,51]. In addition, children under the age of one taking antibiotics (and thus disrupting their gut microbiota) have been associated with pediatric IBD [52]. The composition of the gut microbiome is heavily influenced by early life exposures such as mode of delivery, diet, and environment $[47,53]$. The main bacteria that comprise the gut microbiome include species such as Bacteroidetes, Firmicutes, Proteobacteria, Actinobacteria, Fusobacteria, Verrucomicrobia [54], and Faecalibacterium [55].

These normal gut bacterial species are all reduced in patients with IBD $[54,56]$. One longitudinal study done by Shaw et al in a cohort of pediatric IBD patients discovered a correlation between gut microbial dysbiosis and clinical severity using Pediatric Crohn's Disease Activity Index (PCDAI) score [57]. Of particular interest, Faecalibacterium prausnitzii is believed to play a pivotal role in gut homeostasis by secreting anti-inflammatory factors that interfere with NF-KB activation [58]. Indeed, patients with active IBD have significantlylower levels of F.prausnitzii [55,59] compared to healthy 
controls. These findings all point to an intricate relationship among microbiome, host immunity, and anti-inflammation. Recent studies show that gut viruses, such as enteric viruses [60], and commensal fungi [61] may play a role in gastrointestinal inflammation. More research in this regard is needed to better understand the role that viruses and fungi may play in IBD pathogenesis.

Given the importance of the gut microbiome in potential disease formation, several therapies for IBD have been aimed towards restoring this equilibrium. Fecal microbiota transplantation, which is already being used to treat certain cases of Clostridium difficile infections [62], has shown promising results in the treatment of IBD $[63,64]$. Furthermore, nutritional therapies such as specific carbohydrate diet $[65,66]$ and exclusive enteral nutrition [67] have shown improvement in pediatric IBD patients; however, data are still limited and further research in this area is needed.

\section{Genetics in Pediatric-IBD}

There is increasing evidence that IBD is influenced by genetics. The stable incidence, early age of onset, and characteristic clinical presentation of EO-IBD are strongly suggestive of a genetic etiology $[19,35]$. EO-IBD, frequently unclassifiable into CD and UC, is particularly treatment resistant, and can be related to an underlying primary immune defect [68]. A unique phenotype of EO-IBD has been described in the South Asian pediatric population in British Columbia [69], further supporting the notion of genetics as the cause of EO-IBD. Furthermore, studies have shown that IBD has a sanguineous pattern of inheritance [70] although spontaneous de novo whole gene deletions [71] and mutations in pediatric IBD susceptibility genes [72] have been implicated in disease formation.

Table 1: Genetic mutations in IL-10 and IL-10 receptors and resulting clinical presentation in pediatric IBD.

\begin{tabular}{|c|c|c|c|}
\hline Gene & Mutation & Function & Phenotype \\
\hline IL-10 & Gly113Arg & Missense mutation & $\begin{array}{l}\text { Defective IL-10 protein resulting in an inability to } \\
\text { phosphorylate STAT3[89] }\end{array}$ \\
\hline IL-10 & c.G458A, p.Gly153Asp & Missense mutation in exon 5 & EO- and pediatric IBD[113] \\
\hline IL-10R1 & Gly141Arg , c.C251T & Missense mutation & EO-IBD and folliculitis[30] \\
\hline IL-10R1 & c.C251T, p.Thr84Ile & Missense mutation & Pediatric IBD and folliculitis[30,114] \\
\hline IL-10R1 & Arg262Cys & Missense mutation, signaling defect & VEO-IBD [33] \\
\hline IL-10R1 & p.Arg101Trp, c.C301T & Missense mutation, signaling defect & $\begin{array}{l}\text { EO-IBD, failure to thrive, diarrhea, oral ulcers, } \\
\text { eczema, and perianal fistulas/abscesses[113-115] }\end{array}$ \\
\hline IL-10R1 & p.Tyr57Tyr/Cys, c.A170A/G & Missense mutation & $\begin{array}{l}\text { VEO-IBD, lower extremity arthritis and arthralgias, } \\
\text { and Kawasaki disease[113] }\end{array}$ \\
\hline IL-10R1 & Arg117Arg/Cys & Signaling defect & VEO-IBD[113] \\
\hline IL-10R1 & p.R117H & Missense mutation, signaling defect & VEO-IBD[20] \\
\hline IL-10R1 & c.T506C, p.Ile169Thr & Missense mutation & Pediatric IBD, eczema, and folliculitis[113] \\
\hline IL-10R1 & Pro206X & Premature stop codon & VEO-IBD[90] \\
\hline IL-10R1 & c. $583 \mathrm{~T}>\mathrm{C}$ & Missense mutation & VEO-IBD and functional IL-10RA deficiency[72] \\
\hline IL-10R1 & c. $1368 \mathrm{G}>\mathrm{T}$ & Nonsense mutation & VEO-IBD and functional IL-10RA deficiency[72] \\
\hline IL-10R1 & c.537G > A, p.T179T & $\begin{array}{l}\text { Exon } 4 \text { mutation resulting in a } \\
\text { splicing aberration, signaling defect }\end{array}$ & $\begin{array}{l}\text { VEO-IBD, diarrhea, oral ulcers, eczema, and perianal } \\
\text { fistulas/abscesses[108,115] }\end{array}$ \\
\hline
\end{tabular}

Over 163 genes have been confirmed to be associated with IBD [73-75]. However, only a portion of these genes have been associated with pediatric IBD. Variants in the NOD2, EOIBD [76], IL-23R, ATG16L1, IBD5, TNF- $\alpha$ [77], IL-10, IL-10R [30], XIAP [71], MSH5, CD19 [78], DMBT1 [79], CYBB, CYBA, NCF1, NCF2, NCF4, FOXP3, WAS, MEFV, and ITGB2 have been linked to pediatric IBD. Interestingly, a number of immunity genes such as IL-10 and IL10R have been associated with pediatric IBD. The small and large intestines are the largest source of lymphoid tissue in newborns; therefore, immune dysregulation in response to gastrointestinal microorganisms within the first few weeks of life can lead to inflammation and injury $[68,80]$. Chandrakasan et al in their study categorize EO-IBD as either, a disorder of T-cell immune tolerance, IL-10 signaling, neutrophil function, epithelial barrier function, hyperinflammation, or B-/T-cells [68]. Recently an exome sequencing analysis revealed variants in IL-10RA, MSH5, and CD19 that could lead to primary immunodeficiency in patients with VEOIBD [78].

Accumulating evidence indicates that IL-10/STAT3 pathway is a key player in both pediatric- and adult-onset IBD. IL-10 and STAT3 have been identified as IBD-associated genes in children and adults [16,81-87]. Mutations in IL-10 and IL-10 receptors (IL-10RA and IL-10RB) have been linked to VEO-IBD (Table 1) [20,30,81,8890]. In the following sections, we will discuss in greater detail the GI immune homeostasis and the role of chronic inflammation in IBD. In addition, we will analyze the genetics of the IL-10/STAT3 pathway, including the heme oxygenase 1 (HO-1) gene, in pediatric IBD. 


\begin{tabular}{|c|c|c|c|}
\hline IL-10R1 & c.T192G, p.Tyr64* & Novel mutation & $\begin{array}{l}\text { VEO-IBD, failure to thrive, diarrhea, bloody stools, } \\
\text { and abdominal pain[106] }\end{array}$ \\
\hline IL-10R1 & c.T133G, p.Trp45Gly & Novel mutation & $\begin{array}{l}\text { VEO-IBD, failure to thrive, diarrhea, bloody stools, } \\
\text { and abdominal pain[106] }\end{array}$ \\
\hline IL-10R1 & p.Y91C & Missense mutation & $\begin{array}{l}\text { VEO-IBD, oral ulcers, folliculitis, recurrent } \\
\text { infections, and perianal fistulas[20] }\end{array}$ \\
\hline IL-10R1 & p.W69R & Missense mutation & $\begin{array}{l}\text { VEO-IBD, oral ulcers, folliculitis, recurrent } \\
\text { infections, and perianal fistulas[20] }\end{array}$ \\
\hline IL-10R1 & c. $368-10 \mathrm{C}>\mathrm{G}$ & $\begin{array}{l}\text { Intron } 3 \text { mutation resulting in a } \\
\text { misfolded protein and splicing } \\
\text { aberration }\end{array}$ & $\begin{array}{l}\text { VEO-IBD, diarrhea, recurrent infections, failure to } \\
\text { thrive, and perianal fistula, ulcers, abscesses, and } \\
\text { fissures. No extra-intestinal symptoms.[116] }\end{array}$ \\
\hline IL-10R1 & $\begin{array}{l}\text { Compound heterozygous (c.251C4T, } \\
\text { p.T84I; c.301C4T, p.R101W). }\end{array}$ & Missense mutation & $\begin{array}{c}\text { Autosomal recessive inheritance, VEO-IBD, colitis, } \\
\text { failure to thrive, hematochezia, oral and perianal } \\
\text { ulcers, and pyoderma[114] }\end{array}$ \\
\hline IL-10R1 & rs143538561 Arg412Trp & Missense variant & VEO-IBD, diarrhea, and eczema[78] \\
\hline IL-10R1 & p.V100G & Missense mutation & $\begin{array}{l}\text { VEO-IBD, diarrhea, bloody stools, infections, and } \\
\text { growth delay[109] }\end{array}$ \\
\hline IL-10R1 & pY64C & Missense mutation & $\begin{array}{l}\text { VEO-IBD, diarrhea, bloody stools, and growth } \\
\text { delay[109] }\end{array}$ \\
\hline IL-10R1 & p.P115P, rs2228054 & Mutation at position 175 & EO- and VEO-IBD [90] \\
\hline IL-10R1 & p.I224V, rs2228055 & Mutation at position 224 & EO- and VEO-IBD[90] \\
\hline IL-10R1 \& IL-10R2 & $\begin{array}{l}\text { Compound heterozygous (IL-10RB } \\
\text { E47K and IL-10RA) }\end{array}$ & $\begin{array}{l}-413 \mathrm{G}->\mathrm{T} \text { mutation in IL-10R1 and } \\
\text { IL-10R2 promotor region }\end{array}$ & $\begin{array}{l}\text { VEO-IBD, pancolitis, bloody diarrhea, anemia, and } \\
\text { fatigue[117] }\end{array}$ \\
\hline IL-10R2 & p.Trp159X, c.G477A & Premature stop codon & $\begin{array}{l}\text { VEO-IBD, perianal disease, folliculitis, recurrent } \\
\text { infections, and gonarthritis }[30,113]\end{array}$ \\
\hline IL-10R2 & c.G421T & Premature stop codon & EO-IBD and perianal disease[33] \\
\hline IL-10R2 & c.G197A, p.Cys66Tyr & Missense mutation & VEO-IBD[113] \\
\hline IL-10R2 & c.G611G/A, p.Trp204Trp/X & Missense mutation & VEO-IBD, folliculitis, and weight loss[106,113] \\
\hline IL-10R2 & Ser230Ser/X & Missense mutation & VEO-IBD, dermatitis, and folliculitis[113] \\
\hline IL-10R2 & Trp204X & Missense mutation & EO-IBD and folliculitis[113] \\
\hline IL-10R2 & c. ${ }^{*} \mathrm{C} 52 \mathrm{~T}$ & 3' UTR mutation & VEO-IBD, folliculitis, large joint inflammation[113] \\
\hline IL-10R2 & c.331907_574del & Deletion & VEO-IBD, folliculitis [113] \\
\hline IL-10R2 & p.K47E, rs2834167 & Missense mutation & $\begin{array}{l}\text { VEO-IBD, bloody diarrhea, fever, fatigue, and } \\
\text { anemia[117] }\end{array}$ \\
\hline IL-10R2 & $\begin{array}{l}\text { Heterozygous (p.E141K and } \\
\text { rs387907326) }\end{array}$ & Missense mutation & $\begin{array}{l}\text { VEO-IBD, growth delay, diarrhea, bloody stool, } \\
\text { sepsis, and perianal disease[109] }\end{array}$ \\
\hline
\end{tabular}

\section{Immune Homeostasis in Pediatric IBD}

Inflammation, regulated by pro- and anti-inflammatory cytokines, is the immune response to threats to homeostasis and results in the elimination of foreign pathogens and repair of damaged tissues [91]. Interleukin-1 (IL-1), IL-12, IL-18, tumor necrosis factor, interferon gamma (IFN- $\gamma$ ), and granulocyte macrophage colony stimulating factor are all cytokines which stimulate inflammation. On the other hand, IL-4, IL-10, IL-13, IFN$\alpha$, and transforming growth factor beta are all cytokines which inhibit inflammation [92]. Because IBD is mediated by chronic inflammation, understanding the role of these anti-inflammatory cytokines is vital for IBD clinical therapy. IL-10 is a well-studied anti-inflammatory cytokine in acute and chronic inflammation [93] and plays a key role in regulating gastrointestinal immune homeostasis and inflammation [94,95].

IL-10 knockout mice have been shown to develop IBD [96]. In addition to IL-10, other cytokines are involved in the inflammatory process in IBD. Rafa et al. after analyzing blood plasma from IBD patients showed that the IL-23/IL-17A axis and NO synthase pathway are involved in inflammation regulation in IBD [97]. As illustrated in Figure 1a, signal transduction within the IL-10/STAT3 pathway is initiated by the association of IL-10 to its receptors, IL10RA and IL-10RB. The binding of IL-10 to its receptors creates a receptor complex which then activates JAK1 and Tyk2. JAK1 and Tyk2 are both tyrosine kinases which phosphorylate IL-10RA. IL-10RA then interacts with and activates STAT3 [94,95,98]. STAT3, a transcription factor, then promotes the transcription of anti-inflammatory genes. Functional studies showing STAT3 phosphorylation to IL-10 stimulation in vitro suggest a role for macrophage-intrinsic IL-10R in regulating intestinal homeostasis $[78,95,99]$. Of interest, the HO-1 gene is known to be regulated by IL-10/STAT3 signaling pathway (Figure 1a) $[100,101]$. The HO-1 gene catalyzes the degradation of heme to biliverdin and carbon monoxide. HO-1 has anti-inflammatory properties and has been suggested to have a role in the recovery from IBD. HO-1 also plays 
an important role in regulating intestinal homeostasis through anti-apoptosis and angiogenesis in cancer [102].

\section{IL-10/STAT3 Pathway Mutations in Pediatric IBD}

Given its role in regulating inflammation, it is no surprise that IL-10/STAT3 is involved with IBD. We observed an association between IL-10 SNP rs1800872 and rs304498 with adult IBD in a population of 122 adult IBD with 172 controls, as shown in Figure 1b [103]. There was also an association between IL-10 rs304496 $(p=0.022)$ and rs1800872 (dominant model: $p=0.0277$ ) in pediatric IBD using a case-control [103] and case-trio study [104] respectively. STAT3 was not found to be associated with pediatric IBD in either case-control or case-trio studies [103,104]. New mutations within the IL-10 receptors have recently been identified. IL-10 receptor mutations will block signals from IL-10 and cause inflammation resulting in gastrointestinal tissue damage $[95,105]$. One IL-10RB (cG477A, p.Trp159*) and 2 novel IL-10RA (c.T192G, p.Tyr64* and cT133G, pTrp45Gly) mutations were discovered in a cohort of 17 pediatric patients < 4 years of age [106].

From Chinese populations, 10 novel and 6 previously described mutations were found in IL-10RA and IL-10RB. Of these mutations, IL-10RA (c.C301T, pR101RW; cG537A, pT179T) was the most common [107]. A novel exonic mutation of IL-10RA (cG537A, pT179T) was identified in a child later diagnosed with VEO-IBD [108]. 16 mutations, among which IL-10RA pY64C was a novel mutation, were discovered in the IL-10, IL-10RA, and IL-10RB genes in a cohort of 13 Chinese VEO-IBD patients. The results from the mutation screening indicated that IL-10RA and IL-10RB mutations were associated with the development of VEO-IBD (Table 1) [109]. Our research, using a newly developed method, demonstrated significant epistatic interactions between IL-10 rs1800872 and rs3024496 (additive-additive $\mathrm{p}=0.00015$ ), and between IL-10 rs1800872, rs3024496, and IL-10 RA (additive-additive-additive, $\mathrm{p}=0.003$ ) (Figure 1b) [103]. Hence, understanding more about the gene interactions in the IL-10/STAT3 pathway may be the key to unlocking more knowledge regarding IBD disease formation.

\section{HO-1 as a Potential Player in Pediatric IBD}

Given that HO-1 is regulated by the IL-10/STAT3 pathway, it is reasonable to speculate that $\mathrm{HO}-1$ plays a potent role in controlling inflammation in pediatric IBD. However, using genetic variations of HO-1, a (GT)n dinucleotide repeat within the promoter region and SNP rs2071746 upstream of the HO-1 gene [110], was shown to be neither associated with adult IBD [111,112] nor pediatric CD [111]. In our own research, HO-1 rs2071746 was not associated with pediatric IBD using a case-control study [103]; however, rs2071746 was found to be significantly associated with pediatric IBD using a case-trio study (additive model: $p=1.87 \times 10-4$ ) [104]. In addition, we demonstrated a significant epistatic interaction between HO-1 and different IL-10 and IL-10 receptor SNPs including IL-10 rs1800872 and IL-10 rs2834167 [104] (Figure 1b). These results indicate that HO-1 may be regulated by the IL-10/STAT3 pathway via gene interaction of HO-1 with IL-10 and its receptors.

In order to better understand the anti-inflammatory properties of HO-1 and its interaction with IL-10/STAT3 pathway to regulate immune homeostasis, we analyzed HO-1 gene expression in B lymphocyte cell lines isolated from pediatric IBD cases. Lip polysaccharides (LPS) and TNF- $\alpha$ are well-known pro-inflammatory agents. When exposed to lipopolysaccharides and TNF- $\alpha$, cell lines containing a mutation within the IL-10/STAT3 pathway showed reduced HO-1 gene expression. Therefore, we speculate that the HO-1 gene is a target of regulation by the IL-10/STAT3 pathway and both HO-1 and the IL-10/STAT3 pathway is involved in IBD disease [104].

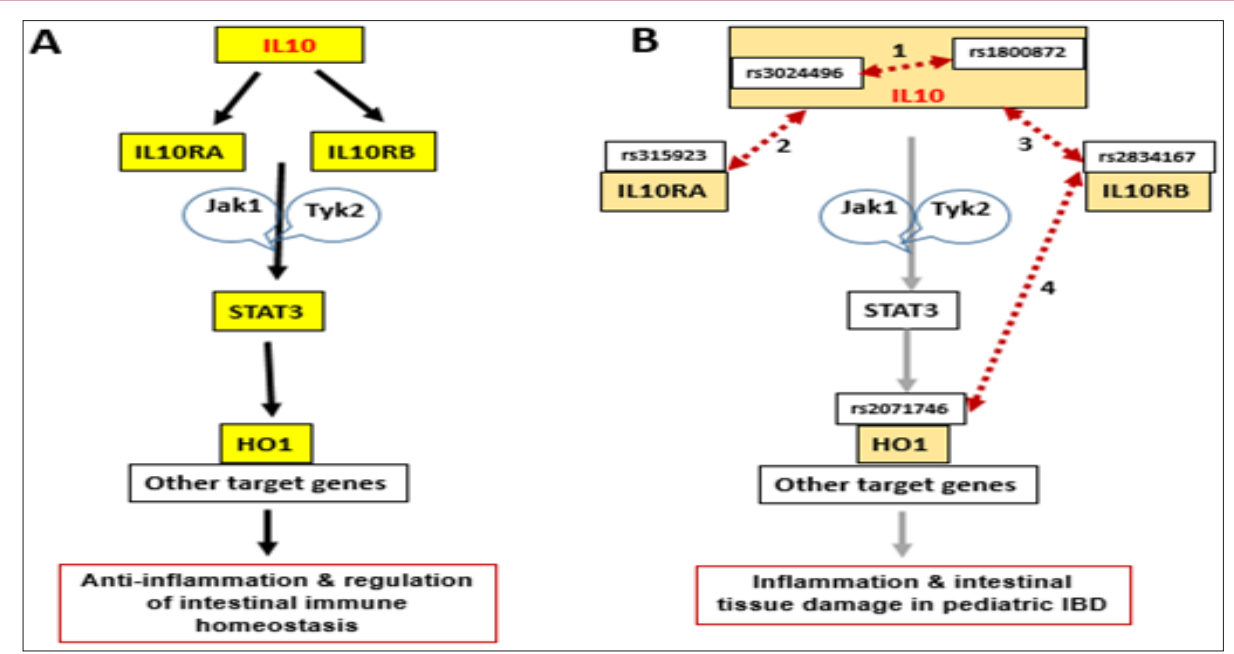

Figure 1: (A) IL-10 binds with its associated receptors and activates JAK1 and Tyk2. In combination with the IL-10 receptor complex, JAK1 and Tyk2 activate STAT3, a transcription factor. STAT3 regulates the transcription of HO-1 and other genes responsible for controlling inflammation and immune homeostasis. (B) Mutations within the IL-10/STAT3 pathway leads to the chronic GI inflammation seen in pediatric IBD. Our research shows the epistatic interactions of SNPs of IL-10, IL-10 receptors, and HO-1. Dotted red arrows show epistatic interactions between (1) different SNPs of IL-10, (2) IL-10 and IL-10RA, (3) IL-10 and IL-10RB, and (4) IL-10RB and HO-1. 


\section{Conclusion}

The available evidence supports the growing belief that EOIBD is determined largely by genetics. Most of these genes are implicated in the immune regulation. The IL-10/STAT3 pathway is a well-studied gene pathway that is involved in maintaining immune homeostasis in both acute and chronic inflammation. IL-10 binds to its associated receptors and forms a complex activating Jak1 and Tyk2. These two proteins then phosphorylate and activate STAT3 that in turn leads to anti-inflammatory gene transcription. SNPs within IL-10, IL-10RA, IL-10RB, and STAT3 have been implicated in both pediatric and adult IBD. In particular, mutations within the IL10 receptors have been shown to associate with VEO-IBD. The IL10/STAT3 pathway regulates the HO-1 gene and the HO-1 gene may be key in understanding EO-IBD pathogenesis. While studies did not find an association between HO-1 and IBD, our case-trio study found a correlation between pediatric IBD and HO-1.

In summary, pediatric IBD, especially EO- and VEO-IBD, has been steadily increasing in incidence in both developed and developing nations. Recent studies show a complicated interplay among the gut microbiome, immune homeostasis, and microbial dysbiosis to be associated with worsening IBD. The IL-10/STAT3 pathway, in addition with the HO-1 gene, plays an important role in IBD pathogenesis. Furthermore, significant epistatic interactions between IL-10 and HO-1 have been identified. Specific investigation into the IL-10 signaling pathway in pediatric IBD pathogenesis will help to better understand pediatric IBD and provide target molecules to potentially develop anti-inflammatory agents for clinical treatment of pediatric IBD.

\section{Acknowledgement}

This work was supported by Children Miracle Network (CMN) Research grant (ZL, JF).

\section{References}

1. Loftus EV (2016) Update on the Incidence and Prevalence of Inflammatory Bowel Disease in the United States. Gastroenterol Hepatol (NY) 12(11): 704-707.

2. Neurath MF (2014) Cytokines in inflammatory bowel disease. Nat Rev Immunol 14(5): 329-342.

3. Bass JA, Friesen CA, Deacy AD, Nancy A Neilan, Julia M Bracken, et al. (2015) Investigation of potential early Histologic markers of pediatric inflammatory bowel disease. BMC Gastroenterol 15: 129.

4. Kim DH, Cheon JH (2017) Pathogenesis of Inflammatory Bowel Disease and Recent Advances in Biologic Therapies. Immune Netw 17(1): 25-40.

5. Fiocchi C (2013) inflammatory bowel disease: evolutionary concepts in biology, epidemiology, mechanisms and therapy. Curr Opin Gastroenterol 29(4): 347-349.

6. Aujnarain A, Mack DR, Benchimol EI (2013) the role of the environment in the development of pediatric inflammatory bowel disease. Curr Gastroenterol Rep 15(6): 326.

7. Farrokhyar F, Swarbrick ET, Irvine EJ (2001) A critical review of epidemiological studies in inflammatory bowel disease. Scand J Gastroenterol 36(1): 2-15.

8. Gupta N, Bostrom AG, Kirschner BS, Cohen SA, Abramson O, et al. (2008) Presentation and disease course in early- compared to later- onset pediatric Crohn's disease. Am J Gastroenterol 103(8): 20922098.

9. Maisawa S, Sasaki M, Ida S, Uchida K, Kagimoto S, et al. (2013) Characteristics of inflammatory bowel disease with an onset before eight years of age: a multicenter epidemiological survey in Japan. J Gastroenterol Hepatol 28(3): 499-504.

10. Nieuwenhuis EE, Escher JC (2008) early onset IBD: what's the difference? Dig Liver Dis 40(1):12-15.

11. Marx G, Seidman EG, Martin SR, Deslandres C (2002) Outcome of Crohn's disease diagnosed before two years of age. J Pediatr 140(4): 470-473.

12. Aloi M, Lionetti P, Barabino A, Guariso G, Costa S, et al. (2014) Phenotype and disease course of early-onset pediatric inflammatory bowel disease. Inflamm Bowel Dis 20(4): 597-605.

13. Molodecky NA, Soon IS, Rabi DM, Ghali WA, Ferris M et al. (2012) Increasing incidence and prevalence of the inflammatory bowel diseases with time, based on systematic review. Gastroenterology 142(1): 46-54.

14. Benchimol EI, Mack DR, Nguyen GC, Snapper SB, Li W, et al. (2014) Incidence, outcomes, and health services burden of very early onset inflammatory bowel disease. Gastroenterology 147(4): 803-813.e7.

15. Vernier-Massouille G, Balde M, Salleron J, Li W, Mojaverian N, et al. (2008) Natural history of pediatric Crohn's disease: a populationbased cohort study. Gastroenterology 135(4): 1106-1113.

16. Benchimol EI, Guttmann A, Griffiths AM (2009) Increasing incidence of paediatric inflammatory bowel disease in Ontario, Canada: evidence from health administrative data. Gut 58(11): 1490-1497.

17. Benchimol EI, Manuel DG, Guttmann A, Nguyen GC, Mojaverian N, et al. (2014) Changing age demographics of inflammatory bowel disease in Ontario, Canada: a population-based cohort study of epidemiology trends. Inflamm Bowel Dis 20(10): 1761-1769.

18. Oliva Hemker M, Hutfless S, Al Kazzi ES, Lerer T, Mack D, et al. (2015) Clinical Presentation and Five-Year Therapeutic Management of Very Early-Onset Inflammatory Bowel Disease in a Large North American Cohort. J Pediatr 167(3): 527-532.

19. Bequet E, Sarter H, Fumery M, Vasseur F, Armengol-Debeir L, et al. (2016) Incidence and Phenotype at Diagnosis of Very-early-onset Compared with Later-onset Paediatric Inflammatory Bowel Disease: A Population-based Study [1988-2011]. J Crohns Colitis 11(5): 519526.

20. Shim JO, Seo JK (2014) Very early-onset inflammatory bowel disease (IBD) in infancy is a different disease entity from adult-onset IBD; one form of interleukin-10 receptor mutations. J Hum Genet. 59(6): 337-341.

21. Kelsen JR, Baldassano RN, Artis D, Sonnenberg GF (2015) Maintaining intestinal health: the genetics and immunology of very early onset inflammatory bowel disease. Cell Mol Gastroenterol Hepatol 1(5): 462-476.

22. De Bie CI, Buderus S, Sandhu BK, De Ridder L, Paerregaard A, et al. (2012) Diagnostic workup of paediatric patients with inflammatory bowel disease in Europe: results of a 5-year audit of the EUROKIDS registry. J Pediatr Gastroenterol Nutr 54(3): 374-380.

23. Zhang YZ, Li YY (2014) inflammatory bowel disease: pathogenesis. World J Gastroenterol 20(1): 91-99.

24. Henderson P, Hansen R, Cameron FL, Gerasimidis K, Rogers P, et al. (2012) Rising incidence of pediatric inflammatory bowel disease in Scotland. Inflamm Bowel Dis 18(6): 999-1005.

25. Malmborg P, Grahnquist L, Lindholm J, Montgomery S, Hildebrand $H$ (2013) Increasing incidence of paediatric inflammatory bowel disease in northern Stockholm County, 2002-2007. J Pediatr Gastroenterol Nutr 57(1): 29-34. 
26. Wang XQ Zhang Y, Xu CD, Jiang LR, Huang Y, et al. (2013) Inflammatory bowel disease in Chinese children: a multicenter analysis over a decade from Shanghai. Inflamm Bowel Dis 19(2): 423-428.

27. AlSaleem K, El Mouzan MI, Saadah OI, AlSaleem B, Al-Hussaini A, et al. (2015) Characteristics of pediatric ulcerative colitis in Saudi Arabia: a multicenter national study. Ann Saudi Med 35(1): 19-22.

28. Cakir M, Unal F, Dinler G, Baran M, Yuksekkaya HA, et al. (2015) Inflammatory bowel disease in Turkish children. World J Pediatr 11(4): 331-337.

29. Gasparetto M, Guariso G, Pozza LV, Ross A, Heuschkel R, et al. (2016) Clinical course and outcomes of diagnosing Inflammatory Bowel Disease in children 10 years and under: retrospective cohort study from two tertiary centres in the United Kingdom and in Italy. BMC Gastroenterol p. 16:35.

30. Glocker EO, Kotlarz D, Boztug K, Gertz EM, Schäffer AA et al. (2009) Inflammatory bowel disease and mutations affecting the interleukin-10 receptor. N Engl J Med 361(21): 2033-2045.

31. Cannioto Z, Berti I, Martelossi S, Bruno I, Giurici N, et al. (2009) IBD and IBD mimicking enterocolitis in children younger than 2 years of age. Eur J Pediatr 168(2): 149-155.

32. Uhlig HH, Schwerd T, Koletzko S, Shah N, Kammermeier J, et al. (2014) the diagnostic approach to monogenic very early onset inflammatory bowel disease. Gastroenterology 147(5): 990-1007.

33. Begue B, Verdier J, Rieux-Laucat F, Goulet O, Morali A, et al. (2011) Defective IL10 signaling defining a subgroup of patients with inflammatory bowel disease. Am J Gastroenterol 106(8): 1544-1555.

34. Ledder O, Catto-Smith AG, Oliver MR, Alex G, Cameron DJ, et al. (2014) Clinical patterns and outcome of early-onset inflammatory bowel disease. J Pediatr Gastroenterol Nutr 59(5): 562-564.

35. Capriati T, Cardile S, Papadatou B, Romano C, Knafelz D, et al. (2016) Pediatric inflammatory bowel disease: specificity of very early onset. Expert Rev Clin Immunol 12(9): 963-972.

36. Nambu R, Hagiwara S, Kubota M, Kagimoto S (2016) Difference between early onset and late-onset pediatric ulcerative colitis. Pediatr Int 58(9): 862-866

37. Buderus S, Scholz D, Behrens R, Classen M, De Laffolie J, et al. (2015) Inflammatory bowel disease in pediatric patients: Characteristics of newly diagnosed patients from the CEDATA-GPGE Registry. Dtsch Arztebl Int 112(8): 121-127.

38. Abraham BP, Mehta S, El-Serag HB (2012) Natural history of pediatric-onset inflammatory bowel disease: a systematic review. J Clin Gastroenterol 46(7): 581-589.

39. Hood HC, Cohen LE, Lee JJ (2011) late adolescent linear growth pattern in pediatric-onset inflammatory bowel disease. J Pediatr Gastroenterol Nutr 53(3): 246-249.

40. El Mouzan MI, Al Mofarreh MA, Saadah OI, Al-Hussaini AA, Al-Saleem $\mathrm{KA}$, et al. (2016) Impact of pediatric inflammatory bowel disease on linear growth: Data from a national cohort study in Saudi Arabia. Saudi J Gastroenterol 22(2): 106-108.

41. Aydemir Y, Pinar A, Hizal G, Demir H, Saltık Temizel IN, et al. (2017) Neutrophil volume distribution width as a new marker in detecting inflammatory bowel disease activation. Int J Lab Hematol 39(1): 5157.

42. Singh H, Nugent Z, Targownik LE, El-Matary W, Brownell M, et al. (2015) Health Care Use by a Population-Based Cohort of Children with Inflammatory Bowel Disease. Clin Gastroenterol Hepatol 13(7): 1302-1309.

43. Canavese G, Villanacci V, Antonelli E, Cadei M, Sapino A, et al. (2017) Eosinophilia - associated basal plasmacytosis: an early and sensitive histologic feature of inflammatory bowel disease. Apmis 125(3): 179-183.
44. Loddo I, Romano C (2015) Inflammatory Bowel Disease: Genetics, Epigenetics, and Pathogenesis. Front Immunol 6: 551.

45. Jensen MD, Andersen RF, Christensen H, Nathan T, Kjeldsen J, et al. (2015) Circulating microRNAs as biomarkers of adult Crohn's disease. Eur J Gastroenterol Hepatol 27(9): 1038-1044.

46. Fofanova TY, Petrosino JF, Kellermayer R (2016) MicrobiomeEpigenome Interactions and the Environmental Origins of Inflammatory Bowel Diseases. J Pediatr Gastroenterol Nutr 62(2): 208-219.

47. Gensollen T, Iyer SS, Kasper DL, Blumberg RS (2016) how colonization by microbiota in early life shapes the immune system. Science 352(6285): 539-544.

48. Abraham C, Cho JH (2009) inflammatory bowel disease. N Engl J Med 361(21): 2066-2078.

49. Cheon JH (2013) Genetics of inflammatory bowel diseases: a comparison between Western and Eastern perspectives. J Gastroenterol Hepatol 28(2): 220-226.

50. Kaser A, Zeissig S, Blumberg RS (2010) inflammatory bowel disease. Annu Rev Immunol 28: 573-621.

51. Kaser A, Blumberg RS (2010) Endoplasmic reticulum stress and intestinal inflammation. Mucosal Immunol 3(1): 11-16.

52. Shaw SY, Blanchard JF, Bernstein CN (2010) Association between the use of antibiotics in the first year of life and pediatric inflammatory bowel disease. Am J Gastroenterol 105(12): 2687-2692.

53. Dominguez-Bello MG, Costello EK, Contreras M, Magris M, Hidalgo G, et al. (2010) Delivery mode shapes the acquisition and structure of the initial microbiota across multiple body habitats in newborns. Proc Natl Acad Sci 107(26): 11971-11975.

54. Eckburg PB, Bik EM, Bernstein CN, Elizabeth Purdom, Les Dethlefsen, et al. (2005) Diversity of the human intestinal microbial flora. Science 308(5728): 1635-1638.

55. Sokol H, Seksik P, Furet JP, Firmesse O, Nion-Larmurier I, et al. (2009) Low counts of Faecalibacterium prausnitzii in colitis microbiota. Inflamm Bowel Dis 15(8): 1183-1189.

56. Eckburg PB, Relman DA (2007) The role of microbes in Crohn's disease. Clin Infect Dis 44(2): 256-262.

57. Shaw KA, Bertha M, Hofmekler T, Pankaj Chopra, Tommi Vatanen, et al. (2016) Dysbiosis, inflammation, and response to treatment: a longitudinal study of pediatric subjects with newly diagnosed inflammatory bowel disease. Genome Med 8(1): 75.

58. Sokol H, Pigneur B, Watterlot L, Lakhdari O, Bermúdez-Humarán LG et al. (2008) Faecalibacterium prausnitzii is an anti-inflammatory commensal bacterium identified by gut microbiota analysis of Crohn disease patients. Proc Natl Acad Sci USA 105(43): 16731-16736.

59. Morgan XC, Tickle TL, Sokol H, Gevers D, Devaney KL, et al. (2012) Dysfunction of the intestinal microbiome in inflammatory bowel disease and treatment. Genome Biol 13(9): R79.

60. Yang JY, Kim MS, Kim E, Cheon JH, Lee YS, et al. (2016) Enteric Viruses Ameliorate Gut Inflammation via Toll-like Receptor 3 and Toll-like Receptor 7-Mediated Interferon-beta Production. Immunity 44(4): 889-900.

61. Iliev ID, Funari VA, Taylor KD, Nguyen Q Reyes CN, et al. (2012) Interactions between commensal fungi and the C-type lectin receptor Dectin-1 influence colitis. Science 336(6086): 1314-1317.

62. Konturek PC, Koziel J, Dieterich W, Haziri D, Wirtz S, et al. (2016) Successful therapy of Clostridium difficile infection with fecal microbiota transplantation. J Physiol Pharmacol 67(6): 859-866.

63. Borody TJ, Khoruts A (2011) fecal microbiota transplantation and emerging applications. Nat Rev Gastroenterol Hepatol 9(2): 88-96. 
64. Khoruts A, Sadowsky MJ (2016) Understanding the mechanisms of fecal microbiota transplantation. Nat Rev Gastroenterol Hepatol 13(9): 508-516.

65. Cohen SA, Gold BD, Oliva S, Lewis J, Stallworth A, et al. (2014) Clinical and mucosal improvement with specific carbohydrate diet in pediatric Crohn disease. J Pediatr Gastroenterol Nutr 59(4): 516521.

66. Suskind DL, Wahbeh G, Gregory N, Vendettuoli H, Christie D (2014) Nutritional therapy in pediatric Crohn disease: the specific carbohydrate diet. J Pediatr Gastroenterol Nutr 58(1): 87-91.

67. Grover Z, Muir R, Lewindon P (2014) Exclusive enteral nutrition induces early clinical, mucosal and transmural remission in paediatric Crohn's disease. J Gastroenterol 49(4): 638-645.

68. Chandrakasan S, Venkateswaran S, Kugathasan S (2017) Nonclassic Inflammatory Bowel Disease in Young Infants: Immune Dysregulation, Polyendocrinopathy, Enteropathy, X-Linked Syndrome, and Other Disorders. Pediatr Clin North Am 64(1): 139-160.

69. Carroll MW, Hamilton Z, Gill H, Simkin J, Smyth M, et al. (2016) Pediatric Inflammatory Bowel Disease Among South Asians Living in British Columbia, Canada: A Distinct Clinical Phenotype. Inflamm Bowel Dis 22(2): 387-396.

70. Karaca NE, Aksu G, Ulusoy E, Aksoylar S, Gozmen S, et al. (2016) Early Diagnosis and Hematopoietic Stem Cell Transplantation for IL10R Deficiency Leading to Very Early-Onset Inflammatory Bowel Disease Are Essential in Familial Cases. Case Reports Immunol.

71. Kelsen JR, Dawany N, Martinez A, Christopher M Grochowski, Kelly Maurer, et al. (2015) A de novo whole gene deletion of XIAP detected by exome sequencing analysis in very early onset inflammatory bowel disease: a case report. BMC Gastroenterol 15: 160.

72. Lee CH, Hsu P, Nanan B, Nanan R, Wong M, et al. (2014) Novel de novo mutations of the interleukin-10 receptor gene lead to infantile onset inflammatory bowel disease. J Crohns Colitis 8(11): 1551-1556.

73. Imielinski M, Baldassano RN, Griffiths A, Russell RK, Annese V, et al. (2009) Common variants at five new loci associated with early-onset inflammatory bowel disease. Nat Genet 41(12): 1335-1340.

74. Xavier RJ, Rioux JD (2008) Genome-wide association studies: a new window into immune-mediated diseases. Nat Rev Immunol 8(8): 631-643.

75. Liu JZ, Van Sommeren S, Huang H, , Ng SC, Alberts R, et al. (2015) Association analyses identify 38 susceptibility loci for inflammatory bowel disease and highlight shared genetic risk across populations. Nat Genet 47(9): 979-986.

76. Connelly TM, Berg AS, Harris L, Brinton D, Deiling S, et al. (2015) Genetic determinants associated with early age of diagnosis of IBD. Dis Colon Rectum 58(3): 321-327.

77. Li X, Song P, Timofeeva M, Xiangrui Meng, Igor Rudan, et al. (2016) Systematic meta-analyses and field synopsis of genetic and epigenetic studies in paediatric inflammatory bowel disease. Sci Rep 6: 34076.

78. Kelsen JR, Dawany N, Moran CJ, Petersen BS, Sarmady M, et al. (2015) Exome sequencing analysis reveals variants in primary immunodeficiency genes in patients with very early onset inflammatory bowel disease. Gastroenterology 149(6): 1415-1424.

79. Muller H, Renner M, Helmke BM, Mollenhauer J, Felderhoff-Muser U (2016) Elevated DMBT1 levels in neonatal gastrointestinal diseases. Histochem Cell Biol 145(2): 227-237.

80. Kawai T, Arai K, Harayama S, Nakazawa Y, Goto F, et al. (2015) Severe and Rapid Progression in Very Early-Onset Chronic Granulomatous Disease-Associated Colitis. J Clin Immunol 35(6): 583-588.

81. Shim JO, Hwang S, Yang HR, Moon JS, Chang JY, et al. (2013) Interleukin-10 receptor mutations in children with neonatal-onset
Crohn's disease and intractable ulcerating enterocolitis. Eur J Gastroenterol Hepatol 25(10): 1235-1240.

82. Seo JK (2011) Pediatric Inflammatory Bowel Disease (IBD): Phenotypic, Genetic and Therapeutic Differences between EarlyOnset and Adult-Onset IBD. Korean J Pediatr Gastroenterol Nutr 14(1): 1-25.

83. Doecke JD, Simms LA, Zhao ZZ, Huang N, Hanigan K, et al. (2013) Genetic susceptibility in IBD: overlap between ulcerative colitis and Crohn's disease. Inflamm Bowel Dis 19(2): 240-245.

84. Ruemmele FM, El Khoury MG, Talbotec C, Maurage C, Mougenot JF, et al. (2006) Characteristics of inflammatory bowel disease with onset during the first year of life. J Pediatr Gastroenterol Nutr 43(5): 603609.

85. Benchimol EI, Fortinsky KJ, Gozdyra P, Van den Heuvel M, Van Limbergen J, et al. (2011) Epidemiology of pediatric inflammatory bowel disease: a systematic review of international trends. Inflamm Bowel Dis 17(1): 423-439.

86. Baldassano RN, Piccoli DA (1999) inflammatory bowel disease in pediatric and adolescent patients. Gastroenterol Clin North Am 28(2): 445-458.

87. Franke A, Balschun T, Karlsen TH, Hedderich J, May S, et al. (2008) Replication of signals from recent studies of Crohn's disease identifies previously unknown disease loci for ulcerative colitis. Nat Genet 40(6): 713-715.

88. Christodoulou K, Wiskin AE, Gibson J, Tapper W, Willis C, et al. (2013) Next generation exome sequencing of paediatric inflammatory bowel disease patients identifies rare and novel variants in candidate genes. Gut 62(7): 977-984.

89. Glocker EO, Frede N, Perro M, Sebire N, Elawad M, et al. (2010) Infant colitis-it's in the genes. Lancet 376(9748): 1272.

90. Moran CJ, Walters TD, Guo CH, Kugathasan S, Klein C, et al. (2013) IL$10 \mathrm{R}$ polymorphisms are associated with very-early-onset ulcerative colitis. Inflamm Bowel Dis 19(1): 115-123.

91. Sirisinha S (2011) Insight into the mechanisms regulating immune homeostasis in health and disease. Asian Pac J Allergy Immunol 29(1): 1-14.

92. Hanada T, Yoshimura A (2002) Regulation of cytokine signaling and inflammation. Cytokine Growth Factor Rev 13(4-5): 413-421.

93. Sabat R, Grutz G, Warszawska K, et al. (2010) Biology of interleukin-10. Cytokine Growth Factor Rev 21(5): 331-344.

94. Hutchins AP, Diez D, Miranda-Saavedra D (2013) The IL-10/STAT3mediated anti-inflammatory response: recent developments and future challenges. Brief Funct Genomics 12(6): 489-498.

95. Shouval DS, Biswas A, Goettel JA, McCann K, Conaway E, et al. (2014) Interleukin-10 receptor signaling in innate immune cells regulates mucosal immune tolerance and anti-inflammatory macrophage function. Immunity 40(5): 706-719.

96. Kuhn R, Lohler J, Rennick D, Rajewsky K, Muller W (1993) Interleukin10-deficient mice develop chronic enterocolitis. Cell 75(2): 263-274.

97. Rafa H, Saoula H, Belkhelfa M, Medjeber O, Soufli I, et al. (2013) IL-23/IL-17A axis correlates with the nitric oxide pathway in inflammatory bowel disease: immunomodulatory effect of retinoic acid. J Interferon Cytokine Res 33(7): 355-368.

98. Carlborg 0, Haley CS (2004) Epistasis: too often neglected in complex trait studies? In: Nat Rev Genet 5: 618-625.

99. Zigmond E, Bernshtein B, Friedlander G, Walker CR, Yona S, et al. (2014) Macrophage-restricted interleukin-10 receptor deficiency, but not IL-10 deficiency, causes severe spontaneous colitis. Immunity 40(5): 720-733. 
100. Brand S (2009) Crohn's disease: Th1, Th17 or both? The change of a paradigm: new immunological and genetic insights implicate Th17 cells in the pathogenesis of Crohn's disease. Gut 58(8): 1152-1167.

101. Murray PJ (2006) Understanding and exploiting the endogenous interleukin-10/STAT3-mediated anti-inflammatory response. Curr Opin Pharmacol 6(4): 379-386.

102. Onyiah JC, Sheikh SZ, Maharshak N, Otterbein LE, Plevy SE (2014) Heme oxygenase-1 and carbon monoxide regulate intestinal homeostasis and mucosal immune responses to the enteric microbiota. Gut Microbes 5(2): 220-224.

103. Lin Z, Wang Z, Hegarty JP, Tony R Lin, Yunhua Wang, et al. (2017) Genetic association and epistatic interaction of the interleukin-10 signaling pathway in pediatric inflammatory bowel disease. World Journal of Gastroenterology 23(27): 4897-4909.

104. Lin Z, Han H, Hegarty JP, et al. (2017) the heme oxygenase-1 gene and inflammatory bowel disease. Swiss Med Weekly 147: w14456.

105. Bernstein CN, Blanchard JF (1999) the epidemiology of Crohn's disease. In: Gastroenterology, United States, 116: 1503-1504.

106. Beser OF, Conde CD, Serwas NK, Cokugras FC, Kutlu T, et al. (2015) Clinical features of interleukin 10 receptor gene mutations in children with very early-onset inflammatory bowel disease. J Pediatr Gastroenterol Nutr 60(3): 332-338.

107. Huang Z, Peng K, Li X, Zhao R, You J, et al. (2017) Mutations in Interleukin-10 Receptor and Clinical Phenotypes in Patients with Very Early Onset Inflammatory Bowel Disease: A Chinese VEO-IBD Collaboration Group Survey. Inflamm Bowel Dis 23(4): 578-590.

108. Yanagi T, Mizuochi T, Takaki Y, Keisuke Eda, Keiichi Mitsuyama, et al. (2016) Novel exonic mutation inducing aberrant splicing in the IL10RA gene and resulting in infantile-onset inflammatory bowel disease: a case report. BMC Gastroenterol 16: 10

109. Xiao Y, Wang XQ, Yu Y, Yan Guo, Xu Xu, et al. (2016) Comprehensive mutation screening for 10 genes in Chinese patients suffering very early onset inflammatory bowel disease. World J Gastroenterol 22(24): 5578-5588.

110. Andersen V, Ernst A, Christensen J, Mette Østergaard, Bent A Jacobsen, et al. (2010) the polymorphism rs3024505 proximal to IL10 is associated with risk of ulcerative colitis and Crohns disease in a Danish case-control study. BMC Med Genet 11: 82.

111. Lenicek M, Duricova D, Hradsky 0 , Dušátková $P$, Jirásková $A$, et al. (2014) the relationship between serum bilirubin and Crohn's disease. Inflamm Bowel Dis 20(3): 481-487.

112. Hausmann M, Paul G, Kellermeier S, et al. (2008) (GT)n dinucleotide repeat polymorphism of haem oxygenase-1 promotor region is not associated with inflammatory bowel disease risk or disease course. Clin Exp Immunol 153(1): 81-85.

113. Kotlarz D, Beier R, Murugan D, Diestelhorst J, Jensen O, et al. (2012) Loss of interleukin-10 signaling and infantile inflammatory bowe disease: implications for diagnosis and therapy. Gastroenterology 143(2): 347-355.

114. Mao H, Yang W, Lee PP, Ho MH, Yang J, et al. (2012) Exome sequencing identifies novel compound heterozygous mutations of IL-10 receptor 1 in neonatal-onset Crohn's disease. Genes Immun 13(5): 437-442.

115. Huang Z, Peng K, Li X, Zhao R, You J, et al. (2017) Mutations in Interleukin-10 Receptor and Clinical Phenotypes in Patients with Very Early Onset Inflammatory Bowel Disease: A Chinese VEO-IBD Collaboration Group Survey. Inflamm Bowel Dis 23(4): 578-590.

116. Murugan D, Albert MH, Langemeier J, Bohne J, Puchalka J, et al. (2014) Very early onset inflammatory bowel disease associated with aberrant trafficking of IL-10R1 and cure by $\mathrm{T}$ cell replete haploidentical bone marrow transplantation. J Clin Immunol 34(3): 331-339.

117. Galatola M, Miele E, Strisciuglio C, Paparo L, Rega D, et al. (2013) Synergistic effect of interleukin-10-receptor variants in a case of early-onset ulcerative colitis. World J Gastroenterol 19(46): 86598670 .

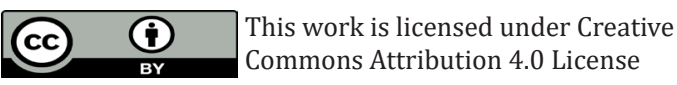

Submission Link: http://biomedres.us/submit-manuscript.php

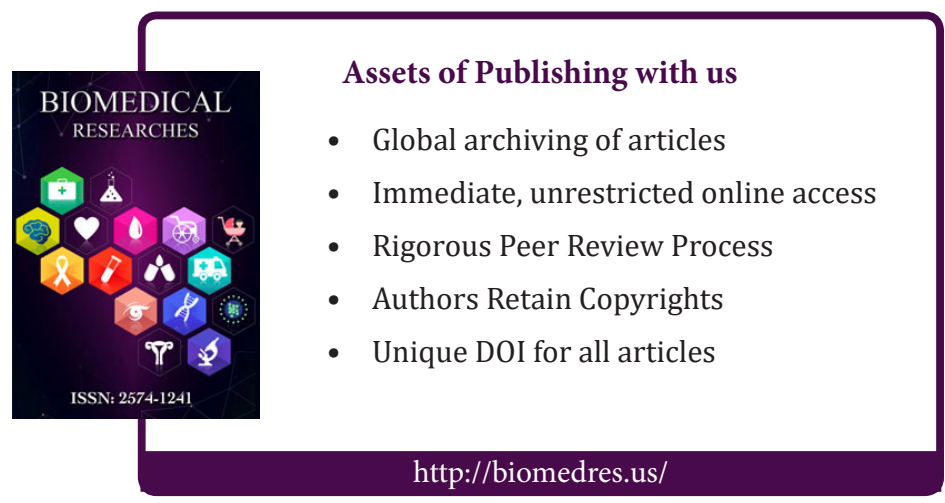

